\title{
Safety assessment for the deficient operation data in the gas-cooled nuclear power plants for hydrogen production
}

\author{
Tae-Ho Woo* \\ Department of Nuclear Engineering, \\ Seoul National University, \\ Gwanak 599, Gwanak-ro, Gwanak-gu, Seoul, 151-742, Korea \\ E-mail: thw@snu.ac.kr \\ *Corresponding author

\section{Tae-Woo Kim} \\ Korea Atomic Energy Research Institute, \\ Daeduk-daero 1045, Yuseong-gu, Daejeon, 305-353, Korea \\ E-mail:kimtw@kaeri.re.kr
}

\begin{abstract}
The probabilistic safety assessment (PSA) is investigated in the case of the operational data shortage which is characteristic of the passive system in gas-cooled nuclear power plants (NPPs). Therefore, it is difficult to make a quantification of the PSA. One of the solutions is to compare the passive system and the active system. Using this comparison, one can find the priority of the passive system reliability. For the modelling, the anticipated transient without scram (ATWS) in the very high temperature reactor (VHTR) and the pressurised water reactor (PWR) is used. Finally, this study decides the difference in the reliability between passive and active systems. The propagation is done by the dynamically modified algorithm (DMA), which highlights the information feedback. The result is analysed by the time changes.
\end{abstract}

Keywords: very high temperature reactor; VHTR; passive system; anticipated transient without scram; ATWS; dynamically modified algorithm; DMA; feedback.

Reference to this paper should be made as follows: Woo, T-H. and Kim, T-W. (2011) 'Safety assessment for the deficient operation data in the gas-cooled nuclear power plants for hydrogen production', Int. J. Nuclear Hydrogen Production and Applications, Vol. 2, No. 3, pp.237-245.

Biographical notes: Tae-Ho Woo has worked in the fields of the system management and reliability of nuclear power plants. He performed his graduate work at the Department of Nuclear Engineering at the Seoul National University, Seoul, Korea. He has written technical papers covering above scientific areas.

Tae-Woo Kim performed his graduate work at the Department of Nuclear Engineering at the Seoul National University, Seoul, Korea. He has worked in the field of nuclear waste management and nuclear power plants in the Korea Atomic Energy Research Institute (KAERI). He has written technical reports covering the above areas. 


\section{Introduction}

The very high temperature reactor (VHTR) of the gas-cooled nuclear power plants (NPPs) has been developed due to the enhanced safety feature of the passive system for the hydrogen production as well as the electricity generation, which is called one of the generation 4 (Gen-4) NPPs (US DOE, 2002). Table 1 shows the historical description of the NPPs' development, where the VHTR is in the generation 4 type. Theoretically, this system is expected as the good safety facility. However, there is a difficulty to make the quantification of the safety assessment in the rare event, since the operational and experience data are deficient. There is no generic data for the natural circulation of long-term cooling, which is considered as the passive system in this study. Hence, the statistical manipulation for the uncommon data is suggested for the data quantification as well as the basic event construction. Additionally, the comparison between the passive system in the VHTR and the active system in the conventional light water reactor (LWR) can decide whether or not the passive system in the NPPs has the priority in the reliability.

Table 1 Generations of the NPPs

\begin{tabular}{lcc}
\hline Generation & Period (year) & Type \\
\hline 1 & $1950-1960$ & Shippingport, Fermi I, Magnox \\
2 & $1970-1990$ & PWR, BWR, CANDU \\
3 & $1990-2025$ & System $80+$, ABWR \\
4 & 2025 & VHTR, SFR, SCWR \\
\hline
\end{tabular}

Table 2 Modified event likelihood of occurrence based on SECY-93-092

\begin{tabular}{lc}
\hline Event & Frequency of occurrence \\
\hline Possible events & $0 \sim 10^{-2} /$ plant-year \\
Non-possible events & $10^{-2} \sim 10^{-4} /$ plant-year \\
Extremely non-possible events & $10^{-4} \sim 10^{-6} /$ plant-year \\
Very rare events & $<10^{-6} /$ plant-year \\
\hline
\end{tabular}

It is examined for the natural circulation of the coolant in anticipated transient without scram (ATWS) scenario of VHTR to be a passive system, because the system is done by the decay heat removal. During the emergency of VHTR, it is a gas type, which is the same phase as the coolant of the normal operation. However, in pressurised water reactor (PWR) of LWR, the phase could be changed from liquid to gas. So, the safety aspect shows a difference in the decay heat removal from the reactor (Burgazzi et al., 2007).

For the licence of construction and operation, it is necessary to meet the safety standards of the regulations. The simulation of the physical value is very important before the operations have been done. Especially, the dynamical investigation is useful to find out the safety assessment in the considerations of the reactor life and the refuelling period when the safety factor could be changed in the failure frequency of the human error for the PWR case.

For the modelling, the comparisons between passive and active systems and the case study for the dynamical reliability in the NPPs are explained in Section 2. The calculation is done in the Section 3 for the probabilistic safety assessment (PSA). Section 4 describes the result of the calculations. 


\section{Modelling for the passive and active systems}

The passive system is different from the active system in the aspect of the safety feature. The passive system is operated by the natural force without any human or electrical forces. In addition, the dynamical transition of the passive system is slow compared with the active system, because there is no hardware failure or human error in the passive system. So, it is important how to treat the safety assessment. This study shows the string concept instead of the event-fault tree concept, since the event scenario is changed to be simpler. Namely, the string can show the complexity of the system. This modified event-fault tree is made in one diagram. Additionally, for the time transition, the feedback string is adjusted, because the time flow is assumed as the non-linear flow. The future happening can be affected in the past time, although any event doesn't happen really. That is to say, an event can affect in the future as well as the past. As a result, the string conuration of the time feedback is constructed for a dynamical assessment.

In this study, the VHTR is a model from the gas turbine-modular helium reactor (GT-MHR) of the General Atomics. Some gas-cooled NPPs are considered for the design basis accidents (DBA), which are mostly non-commercialised research reactors. The DBA was constructed by the Korea Atomic Energy Research Institute (KAERI). The DBA of the PWR is also constructed by the KAERI. This safety parameter of the ATWS is based on the report of the KAERI (2007). This data is used to find the failure frequency by nuclear fuel. Namely, the maximum failure frequency is at $1,250^{\circ} \mathrm{C}$, although there is the maximum nuclear fuel temperature at $1,600^{\circ} \mathrm{C}$. There is the simplified natural circulation for VHTR in Figure 1.

Figure 1 Simplified configuration of natural circulation in VHTR (see online version for colours)

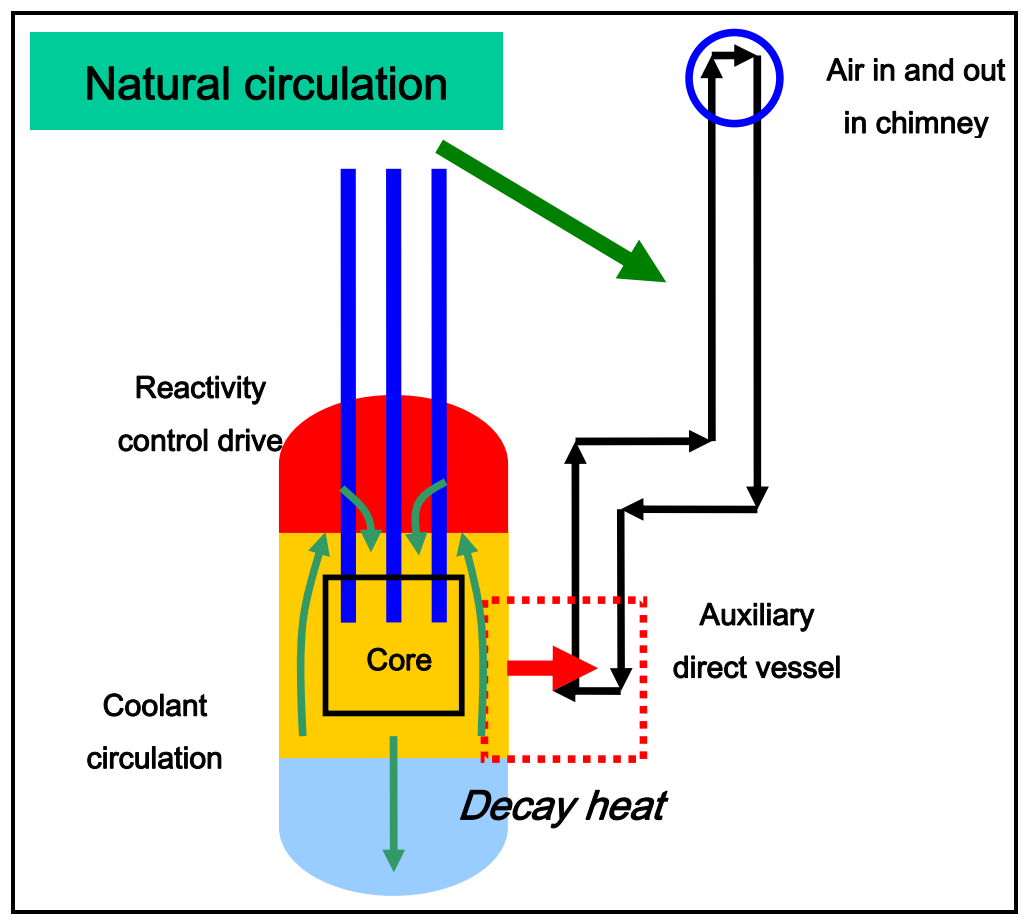




\section{Calculations of the simulations}

For the failure frequency of the basic event, there are two kinds of the rules. In the passive system, the mass flow rate and the fuel temperature are obtained by the GAMMA code simulation (No et al., 2007) in Figure 2. The maximum temperature of each mass flow rate case is the representative value. For example, the blue arrow line shows the maximum temperature in the case of $12.6 \mathrm{~kg} / \mathrm{s}$ mass flow rate. Using this relationship, the failure fraction is obtained in Figure 3 by taking the temperature value, which is from the General Atomics. So, the blue arrow line shows the $10^{-2}$ of the failure fraction. The fraction is regarded as the failure frequency. So, the failure frequency is as;

$$
\begin{aligned}
\text { Failure frequency }= & (\text { Failure frequency of the initiating event }) \\
& \times(\text { Failure fraction of the fuel })
\end{aligned}
$$

Figure 2 Temperature vs. mass flow rates for maximum fuel temperature using GAMMA code (see online version for colours)

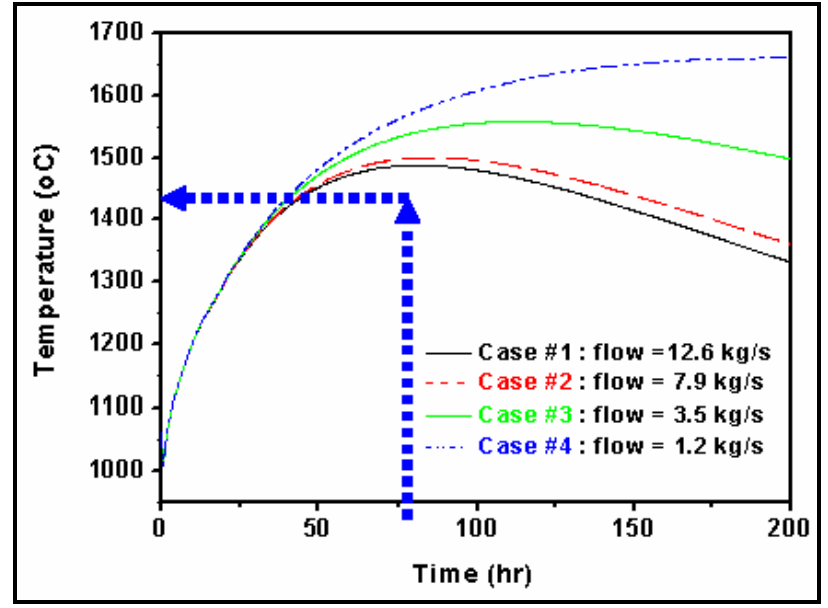

Figure 3 Fuel temperature vs. failure fraction (see online version for colours)

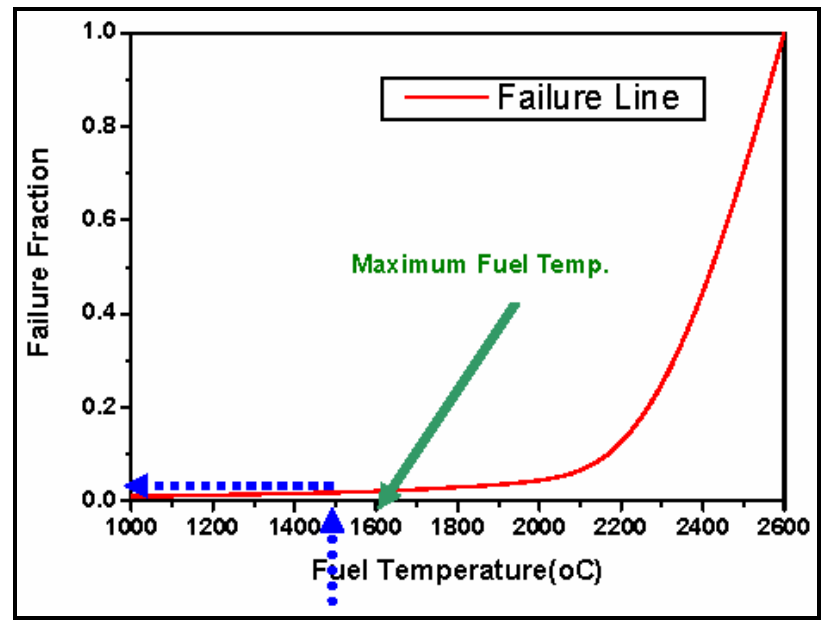


Figure 4 Data quantification (VHTR) (a) event-fault tree (b) feedback string (see online version for colours)

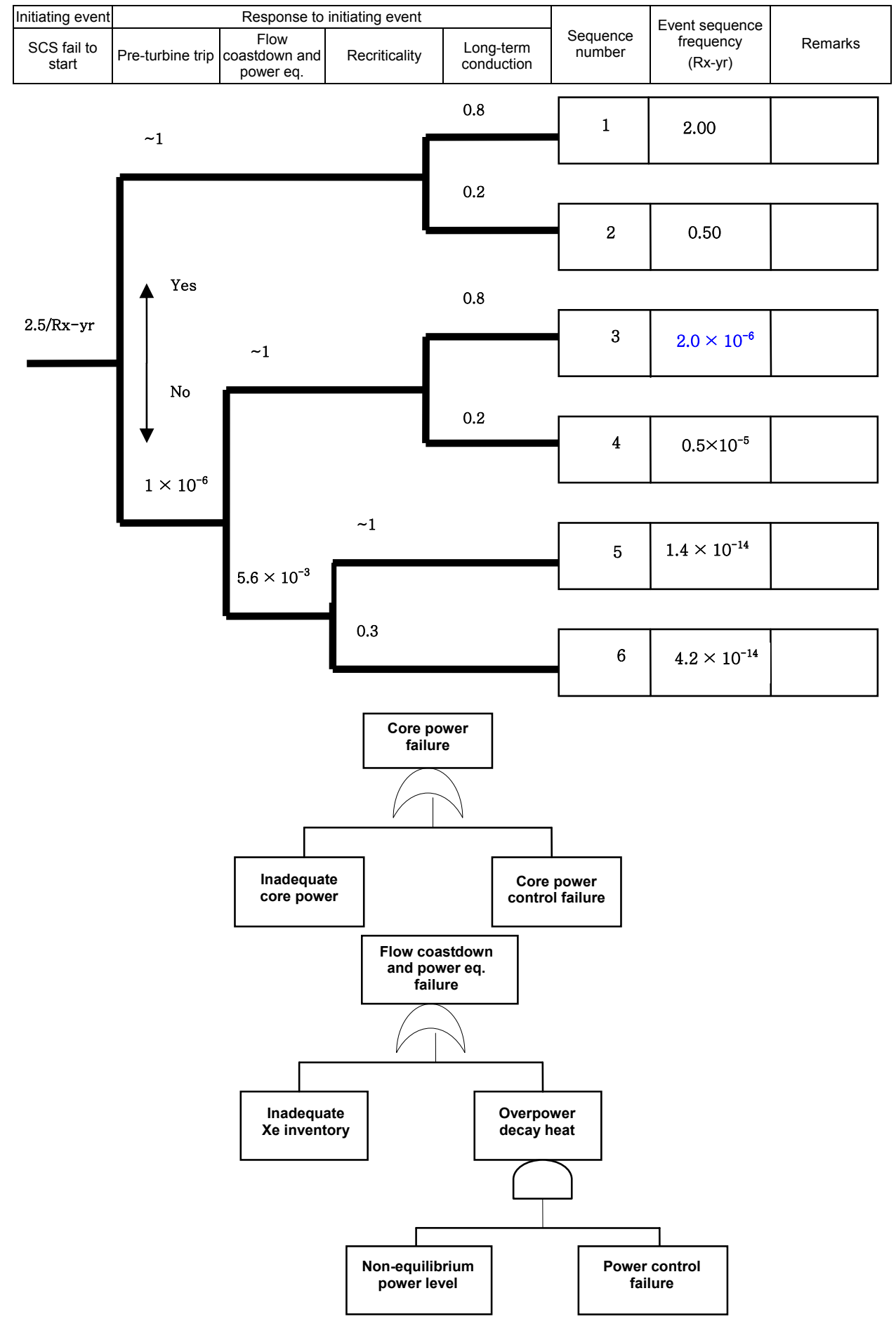

(a) 
Figure 4 Data quantification (VHTR) (a) event-fault tree (b) feedback string (see online version for colours) (continued)

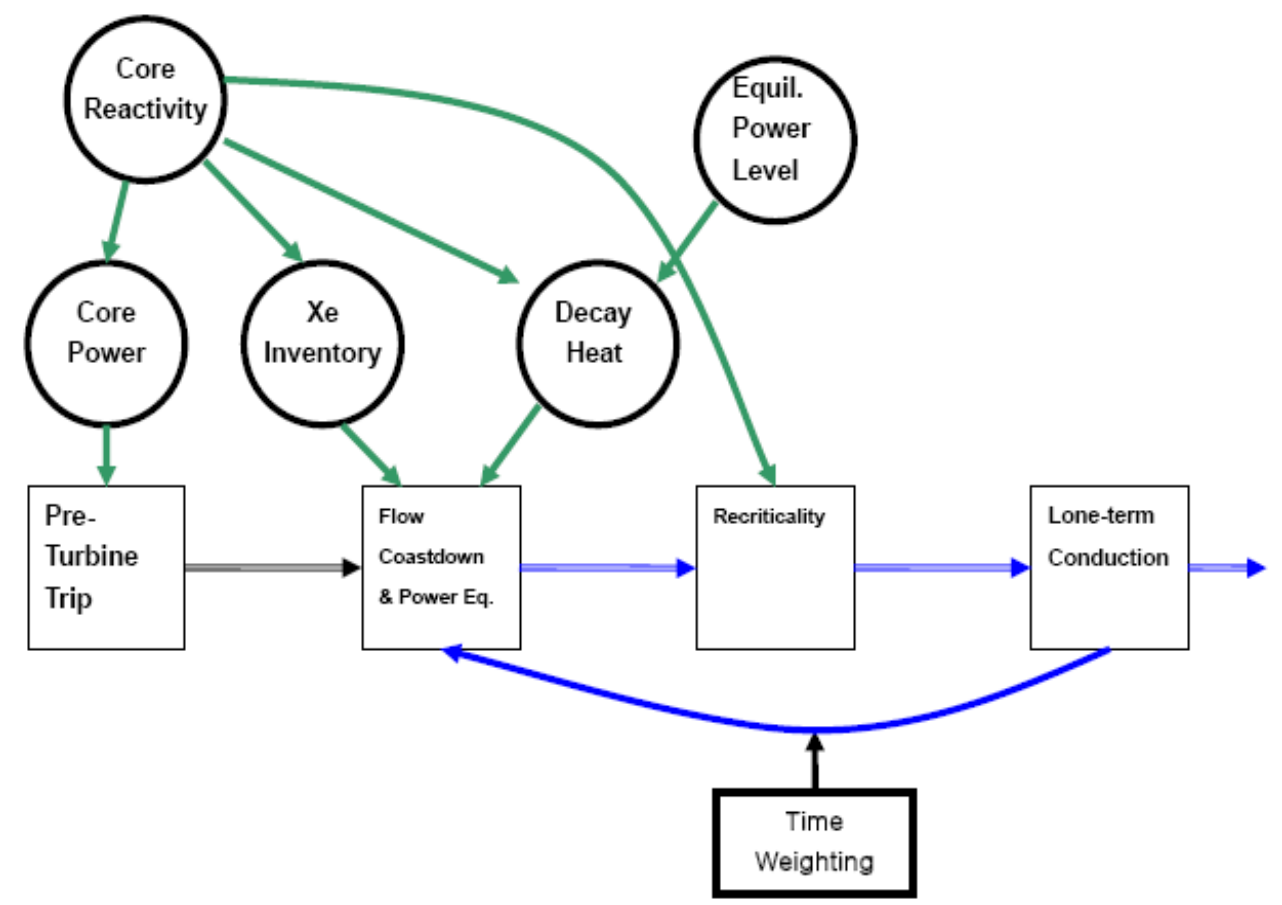

(b)

This means the failure frequency of the long-term cooling is normalised as the failure frequency of the initiating event. This results that the failure frequency is related to the mass flow rate of the ATWS. For the PWR, the failure frequency of the basic event is obtained from the modified data from the US NRC (1993). After using the event-fault tree, the scenario is applied to the string concept. Using the string concept, the future event is affected by the past event and vice versa. The trees are modified by the time feedback algorithm. The results are taken by the quantification of the Monte-Carlo simulation.

There are modified event-fault trees for the VHTR and PWR. Figure 4(a) shows the event-fault tree jointed configuration and Figure 4(b) shows the information feedback oriented string type configuration for VHTR. For the dynamically modified algorithm (DMA), the event-fault tree is modified using the non-linear string and the time feedback is adjusted. So, the simplified complex algorithm is constructed. This method was introduced as the dynamic resistance-stress method (DRSM) (Woo et al., 2009). The linear event flows are changed to string or loop type event flows where the directions of event flows are changed with a relevant weighting. This weighting is decided by the judgment of the operator. The Figure 5 shows the information feedback oriented string type configuration for PWR, which is constructed similarly with the case of the Figure 4. 
Figure 5 Data quantification (PWR) using feedback string (see online version for colours)

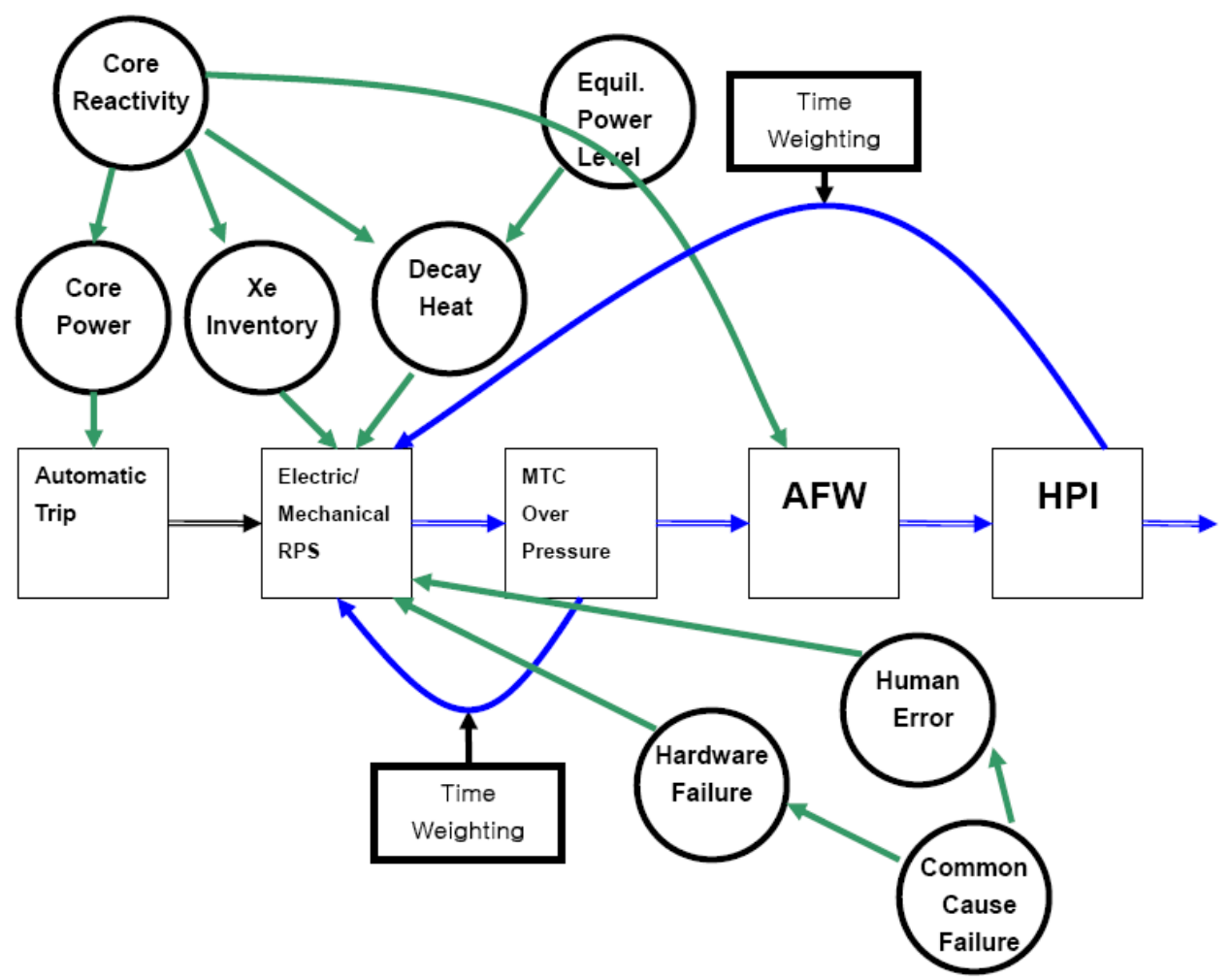

\section{Results and discussions}

The result for the frequency by the time transition is in Table 3. The ATWS of the VHTR is compared with that of the PWR. In the event tree, the blue colour one is the value of the DMA calculation. The failure frequencies of the basic event are obtained by the VHTR for the passive system and by the PWR for the non-passive system, respectively. The failure frequency of the VHTR is higher than that of the PWR. Since the DMA string in VHTR is simpler than the PWR's case, it is thought that the time weighting factor makes the above result which shows the better reliable system in the PWR's case. Simulation is done during 40 years and the refuelling period is assumed as every 15 months for the VHTR and PWR, although the commercialised PWR is the 18 months period. In Table 3, there is the percent rate of the difference between the failure frequency of the VHTR and the PWR as:

Percent rate $(\%)=\{($ the failure frequency of the PWR - the failure frequency of the VHTR $)$ /(the failure frequency of the VHTR) $\} \times 100$

The result shows the higher value when the life time is after five years operation. However, the failure frequency is lower than cases of other time, which means the failure frequency doesn't match with the comparative frequency rate in this modelling. The 
similar cases are shown in the time of the starting point and in the time after four years and 35 years operations.

Table 3 Failure frequency of the PWR and VHTR

\begin{tabular}{lccc}
\hline Time (month) & $P W R(1 / R x-y r)$ & VHTR $(1 / R x-y r)$ & Rate of percent $(\%)$ \\
\hline 1 & $5.81116 \mathrm{E}-20$ & $6.11971 \mathrm{E}-17$ & 97.33034 \\
30 & $7.72045 \mathrm{E}-14$ & $8.04750 \mathrm{E}-11$ & 97.27422 \\
60 & $7.16007 \mathrm{E}-18$ & $7.49333 \mathrm{E}-15$ & 97.29632 \\
90 & $6.10892 \mathrm{E}-16$ & $6.37626 \mathrm{E}-13$ & 97.28165 \\
120 & $2.59611 \mathrm{E}-14$ & $2.70666 \mathrm{E}-11$ & 97.27541 \\
150 & $4.75929 \mathrm{E}-15$ & $4.96407 \mathrm{E}-12$ & 97.27776 \\
180 & $4.32620 \mathrm{E}-14$ & $4.50996 \mathrm{E}-11$ & 97.27483 \\
210 & $2.75905 \mathrm{E}-15$ & $2.87824 \mathrm{E}-12$ & 97.27867 \\
240 & $1.49193 \mathrm{E}-13$ & $1.55495 \mathrm{E}-10$ & 97.27359 \\
270 & $1.25343 \mathrm{E}-13$ & $1.30642 \mathrm{E}-10$ & 97.27375 \\
300 & $9.19130 \mathrm{E}-16$ & $9.59200 \mathrm{E}-13$ & 97.28077 \\
330 & $1.19143 \mathrm{E}-14$ & $1.24240 \mathrm{E}-11$ & 97.27641 \\
360 & $1.21443 \mathrm{E}-13$ & $1.26578 \mathrm{E}-10$ & 97.27378 \\
390 & $6.13021 \mathrm{E}-14$ & $6.39017 \mathrm{E}-11$ & 97.27445 \\
420 & $9.92980 \mathrm{E}-17$ & $1.03732 \mathrm{E}-13$ & 97.28639 \\
450 & $7.81026 \mathrm{E}-16$ & $8.15126 \mathrm{E}-13$ & 97.28112 \\
480 & $2.86354 \mathrm{E}-15$ & $2.98721 \mathrm{E}-12$ & 97.27861 \\
\hline
\end{tabular}

\section{Conclusions}

The non-linear string based PSA is experimented, where this quantification could substitute with the tree type in PSA. The VTHR is tested with the PWR for the long-term cooling. This method could be used for the VHTR safety analysis. The DMA can be applied to the new generation NPPs for the safety system. However, for the final quantifications in the ATWS case, the active system of PWR has the better reliability. So, it is concluded that the stability of the reliability for a decision making depends on the event scenario as well as the failure frequency of the basic event. The other particular meanings of this study are as follows;

- the DMA is tested with the event-fault tree for the safety analysis

- for the simplification, a dynamic logic is performed using the time feedback string

- the event tree and fault tree are expressed easily in one-string diagram

- the passive and active systems in NPPs are compared respectively using DMA

- the colourful expression is possible

- this new PSA method can be applied to the licence construction. 
For the further study, it is necessary to study how to increase the safety standard using non-linear DMA. There are several kinds of non-linear algorithm like the artificial intelligence. The advanced safety assessment methodology could be used to make better NPPs.

\section{Acknowledgements}

The authors would like to thank Dr. W.J. Lee and Dr. H.S. Lim of Korea Atomic Energy Research Institute in Korea for their research discussions.

\section{References}

Burgazzi, L. et al. (2007) 'State of the art in reliability of thermal-hydraulic passive system', Reliability Engineering \& System Safety, Vol. 92, pp.671-675.

No, H.C. et al. (2007) 'Multi-component diffusion analysis assessment GAMMA code and improved RELAP5 code', Nucl. Eng. and Design, Vol. 237, pp.997-1008.

Screening of Gas-Cooled Reactor Thermal-Hydraulic and Safety Analysis Tools and Korea Atomic Energy Research Institute (KAERI) (2007) 'Experiment database', I-NERI Final Project Technical Report, Korea.

US DOE (2002) A Technology Roadmap for Generation IV Nuclear Energy Systems, Washington, USA.

US NRC (2003) Regulatory Effectiveness of the Anticipated Transient without Scram Rule, NUREG-1780, Washington, USA.

Woo, T.H. et al. (2009) 'Dynamical reliability of the passive system in the very high temperature gas cooled reactor', Annals of Nuclear Energy, Vol. 36, pp.1299-1306. 